\title{
Research on the Construction of Internal Quality Assurance System in Higher Vocational Colleges and Its Practice
}

\author{
Ming Zeng \\ Hunan Modern Logistics College \\ Changsha, China
}

\begin{abstract}
The diagnosis and improvement of internal quality assurance system is a necessary means to improve the comprehensive strength of higher vocational colleges. Since the Ministry of Education put forward the requirement of carrying out the construction of internal quality assurance system in higher vocational colleges, the teaching diagnosis and improvement of higher vocational colleges have been promoted comprehensively, and the construction of internal quality assurance system has begun to appear, which will directly affect the high-quality development of higher vocational colleges. In order to establish a normalized independent guarantee mechanism, Hunan Modern Logistics College combs the connotation of the internal quality assurance system of the school, expounds the principles and methods of the construction of the internal quality assurance system of higher vocational colleges, especially takes the actual construction system as an example, clarifies the ideas and paths of the system construction, and effectively solves the key problems in the system construction.
\end{abstract}

Keywords-higher vocational colleges; internal quality assurance; system construction; diagnosis and improvement

\section{INTRODUCTION}

In 2015, the general office and the department of vocational \& adult education of the Ministry of education issued documents to indicate that higher vocational colleges are required to establish and improve their own internal quality assurance system and put the construction of the internal quality assurance system in the most prominent position of the reform and development of higher vocational colleges. The internal quality assurance work of higher vocational colleges has received unprecedented attention. Therefore, it is necessary to clarify the connotation of the internal quality assurance system of higher vocational colleges and build the principle and practice mode of schools internal quality assurance system has become the first important issue to be solved by relevant managers, researchers and practitioners. Hunan modern logistics college attaches great importance to the diagnosis and improvement work, lists the diagnosis and reform work as the "number one project" of the school, and sets up the diagnosis \& improvement leading group, expert committee, special organization for diagnosis \& improvement and ten special working groups of the internal quality assurance system, focusing on the system construction and performance evaluation, to carry out the "three projects" and "three assessments" in depth, through the calibration and refinement of the school plans, according to the weekly arrangement, the monthly dispatch, the annual assessment of the three levels of work, comprehensively carry out the teaching work diagnosis and improvement, found a new way, formed the school's characteristic "23313" internal quality assurance system working mechanism, achieved actual results in system construction, performance assessment and other aspects through the two wheel drive mode of leading and promoting. In terms of the construction and operation of internal quality assurance system, it has been actively exploring practice, which has important reference and Enlightenment for higher vocational colleges.

\section{CONNOTATION OF INTERNAL QUALITY ASSURANCE SYSTEM}

In the mid-1980s, European countries took the lead in the efforts and attempts of quality assurance system construction, and then rapidly expanded to the United States, Canada, Australia and other developed countries. In the 1990s, the construction of quality assurance system became a worldwide upsurge, and more than 180 systems with their own characteristics have been established in the world. According to the research of scholars, the quality assurance system is a quality management system established by an organization to perform its management functions. This organization may be a government functional department, a third party of the society, or a higher vocational college itself. The system led by higher vocational colleges is an internal quality assurance system. The purpose of the construction of the quality assurance system is to enhance consumers' trust in the school running quality; The basic elements of quality assurance system include quality organization system and quality procedure system. The construction of quality assurance system should first establish a scientific organization system, specifically quality assurance command system, standard system, information collection and processing system, evaluation, feedback and improvement system, as well as the human and financial support system to ensure their operation. Secondly, the construction of quality assurance system needs to strengthen the work program 
design, and every link affecting the work quality should be based on reasonable procedures.

Some scholars think that the quality assurance system of higher education is based on the quality culture with the constant pursuit of perfect education quality as the core, and the combination of internal and external. Scholars holding this view first agree that the quality assurance system is the organizational system and procedural system of quality management, and the effective quality assurance system is the organic combination of external and internal guarantee, the inner oriented and a real lasting quality is based on the school's self-improvement. Quality assurance is the inheritance and development of education evaluation. Establishing reasonable evaluation indexes and standards, organizing stakeholders to participate in quality evaluation activities, discovering and improving problems in quality practice in time are the most core means of quality assurance. Combining the views of different students and the reality of higher vocational education, the main points of this paper are as follows:

First, the construction of quality assurance system is the conscious action of the school in pursuit of perfect quality. On the one hand, it should base on the organization, system and cultural foundation of school quality management; on the other hand, it should pursue the continuous improvement and development of quality management concept, content, method, technology and art. The object of quality assurance can be the comprehensive school running quality, the single quality of personnel training, scientific and technological research, social services, cultural heritage and innovation, and even the specific work quality of professional education, quality education, curriculum construction, practice base construction, teaching staff construction, financial asset management, logistics service and so on.

Second, enhancing the trust of stakeholders is the starting point of quality assurance system construction. Higher vocational colleges are typical stakeholder organizations. Once the stakeholders lose interest in the school, the survival of the school will be difficult to sustain; if the internal stakeholders such as teachers, students, managers lose confidence in the school, the development of the school will bury hidden dangers. The quality concept of "the quality of higher vocational education is the degree to which all the work of Higher Vocational Colleges meets the needs of stakeholders" is generally accepted by people. People attach importance to the demands of stakeholders and bring them into the quality management system, which is increasingly recognized by people.

Third, the quality assurance system of higher vocational colleges is a relatively independent system. The standard system composed of quality standards is to make clear the contents, procedures and methods of each work, so that the quality practice activities can be based on rules and evidence, and always keep the right direction and route; the evaluation system composed of diagnosis, feedback and improvement is to find problems through diagnosis, eliminate the potential risks of problems to quality through improvement, and constantly improve the quality; and Source support system, relying on reasonable organizational structure, high-quality human and property resources, flexible information exchange, management system with good incentive and restraint function, and striving campus culture, makes quality production and management orderly, low consumption and high efficiency.

\section{CONSTRUCTION PRINCIPLES OF INTERNAL QUALITY ASSURANCE SYSTEM}

\section{A. Strengthening the Combination of Leadership and All Staff Participation}

Dai Ming, a great master of quality management, points out that most of the quality problems are caused by poor process design and poor organization management. They all point to the managers of the organization. Quality management must start with improving the quality of managers. The Party committee of higher vocational colleges must strengthen the leadership of the construction of quality assurance system, and the administrative team headed by the president must promote the system construction on the ground. If the construction of quality assurance system can still be completed by a few management and academic "elites", the operation of quality assurance system can only rely on the joint efforts of all stakeholders. All staff participation is the thought essence of modern quality management. In fact, it is the inevitable requirement of quality management to implement all staff quality responsibility and improve all staff quality ability. Management departments regularly check the rationality and feasibility of the quality system, which is an improvement organization that is composed of students, teachers, teaching assistants and senior managers in Higher Vocational Colleges and actively participate in it, so as to continuously improve the quality.

\section{B. Coordination of Improving System and Shaping Spirit}

The positive interaction between system and spirit can promote the orderly development of the school. Teachers and students who are looking forward to the effectiveness of quality management must work hard on system construction and spirit shaping. Comenius pointed out that "the system is the soul of all the work of the school, where the system shakes, there will be all the shakes; where the system is loose, there will be all the looseness and confusion". The understanding of quality and its management cannot stay at the level of "regulated" such as standard, specification, diagnosis and improvement. "Although the technical means of quality management and guarantee play an important role in the improvement of the quality of higher education, it cannot fundamentally solve the problem of quality improvement. Only based on the willingness of all teachers and students to take the initiative to ask for improvement and establish a quality culture deeply rooted in the hearts of the people, can it fundamentally establish a long-term mechanism for improving and improving quality. "Therefore, it is an equally important task in the construction of quality assurance system and system to cultivate the quality 
schools to establish an internal quality assurance system suitable for their own characteristics, takes the establishment of independent diagnosis and improvement mechanism of internal quality assurance system as the basic requirement, takes the spot check of provincial (municipal) education authorities as the promotion measure, and strengthens the main position of higher vocational colleges in the quality of higher vocational education by taking the spot check and review of provincial (municipal) education authorities as the promotion measures, strengthen the main position of higher vocational colleges in the quality of higher vocational education and realize the shift of the focus of quality assurance to front-line producers and managers. At present, higher vocational colleges must understand the connotation of quality assurance, grasp the basic laws to be followed in the construction of quality assurance system, focus on the construction of school internal quality assurance system, combine the construction of internal quality assurance system with external quality assurance activities, and jointly promote the improvement of school running level.

\section{CONSTRUCTION PRACTICE OF INTERNAL QUALITY ASSURANCE SYSTEM} system and its resources focuses on input quality, implementation of process management, discovery, feedback and improvement of problems focus on process quality, performance evaluation, measurement, analysis and improvement of performance focus on output quality and system efficiency, performance evaluation is the content of quality management, performance management is not dispensable; academic freedom is academic activity iron law. As an academic organization, a considerable part of the work standards of vocational colleges are mainly qualitative and quantitative supplemented, process monitoring is mainly elastic and rigid supplemented, standards and monitoring are loose, and strict implementation of rules \& regulations and performance evaluation can ensure that schools Fierce competition is invincible.

\section{Internal and External Guarantees Work in Cooperation with Each Other}

Historically, the quality assurance of higher education begins with a strong external guarantee. With the deepening of theoretical research and practical exploration, people gradually realize that effective quality assurance must be based on the combination of internal and external, give priority to the inside and promote the interior by the outside. External quality audit, supervision, demonstration and other evaluation activities can guide, motivate and restrain quality practice, but "excessive external accountability often restricts internal improvement. Sometimes, the more external attention is paid to internal improvement, the more difficult it is to implement internal improvement. Instead, it increases the risk of superficial obedience and negative response, takes the external promotion of internal establishment and operation as the value orientation, guide and urge schools to form a quality assurance mechanism of self-examination, self-introspection and self-discipline. On the basis of summarizing the experiences and lessons evaluation of the work level of the personnel training and the evaluation of the of the work of the personnel training, it focuses on guiding

\section{A. Schools: Planning Guidance, System Promotion, and Improvement of School Governance Level}

1) Building the target chain of diagnosis and reform under the guidance of planning construction: The "source" of the diagnosis and reform work is the school's various plans. The school system has scientifically formulated the 13th Five year development plan of the school, the 13th Five year plan of the school's basic construction, the 13th Five year special specialty system construction plan, the 13th Five year faculty construction plan, the 13th Five year plan of international cooperation and exchange, the school Campus culture construction plan, the School intelligent campus overall construction Design plan and other 15 development plans, based on various plans, have defined the construction objectives of each major, improved the construction objectives of each course, formulated the career development objectives of each teacher, set up the growth and talent objectives of each student, and accurately built the goal chain from five levels of school, major, course, teacher and student.

2) Building a new normal of governance with the promotion of system construction: The school focuses on the system construction as the basis of the diagnosis and improvement work, reorganizes various rules and regulations, completes the top-level design, according to the requirements of superior documents and policies, all departments improve, reorganize and optimize on the existing basis, establish a standardized and scientific system, and optimize the internal governance structure of the school. Over the past year, through the clarification of the process, the establishment of an internal control mechanism for matching the process with the system, and the comprehensive establishment of the quality assurance 
training specification standard; curriculum construction standard system consists of curriculum development standard, teaching design standard, teaching operation standard and curriculum management standard and so on. A total of 84 standards were developed throughout the year, including 28 professional standards at the school level, 75 curriculum standards for co-construction between schools and enterprises, 23 internationally recognized curriculum standards hosted 6 provincial construction standards and hosted 3 national teaching standards, the work of school education and teaching is constantly standardized, and there are standards to follow in everything. The professional diagnosis and improvement has achieved preliminary results.

\section{Teachers: Leading by Famous Teacher Project, Promoting Three Examinations, and Improving the Level of Teachers' Ability}

1) Building a development community with the construction of famous teachers as the guide: In order to effectively stimulate the personal development of school teachers, promote the overall development with the team, improve the quality and professionalism of teachers in an all-round way, and strengthen the construction of a leading backbone teacher team, the school issued the Trial Measures for famous teacher project, which set up 21 famous teacher studios and 6 famous teacher teams in total. The participation of school teachers reached $65 \%$, and a community for the overall development of teachers was constructed, school teachers formed a good situation of catching up with each other and advancing together, and their personal energy has been effectively stimulated.

2) Promoting teachers' professional level with three assessments: In order to promote the scientific research level and service ability of teachers to a new level, and further improve the quality of education \& teaching and the professional level of teachers, the school issued the Assessment method for personal scientific research work, the Assessment method for teaching quality and the Hierarchical and classified management system for teachers, which divides teachers into three levels: primary level, intermediate level and senior level, three categories of scientific research, teaching and skills. Each level and each category establish the corresponding criteria. Each full-time teacher established a personal career plan for the standard. At the end of the year, the school carries on the standard examination from three aspects: education and teaching, scientific research and skill competition. In the whole year, the amount of vertical and horizontal scientific research funds increased by $260.67 \%$ and $357.30 \%$ respectively, which effectively improved the teachers' social service ability, education and teaching level, scientific research leading ability and so on. 
D. Curriculums: Leading Demonstration Courses, Promoting Supervision and Evaluation, and Improving Classroom Teaching Quality

1) Taking the demonstration class as a guide to create a golden class for classroom teaching: In order to give full play to the exemplary role of outstanding teachers in the teaching process, improve the quality of teachers 'classroom teaching, and enhance teachers' classroom teaching ability, in 2018, 16 outstanding teacher teaching demonstration class observation activities were conducted, attracting more than 200 teachers from schools to observe, effectively promote the growth of young teachers, external teachers and new teachers, demonstrate excellent classes, further promote teachers to build a good course and teach a good course, construct and build 30 school level online open courses, with $100 \%$ students' participation, $97 \%$ completion rate of students' courses, establish credit bank and conversion system, project 2 provincial excellent online open courses, set up 2 provincial quality online open courses, establish a national teaching resources alternative library, golden course construction has taken a substantive step to effectively improve the quality of the course.

2) Promoting the effect of classroom teaching by supervision and evaluation: Through the establishment of special supervision week, collective lesson preparation and $100 \%$ full coverage system for teachers to attend classes, all members of the school Steering Committee comprehensively attend four types of teachers in the whole school, including full-time teachers, part-time teachers in school, part-time occupation outside the school, part-time class outside the school, collect and sort out the "teacher's classroom teaching quality evaluation form", establish dynamic data, and feed back to them in time the teachers who have been listened to have formed a dynamic monitoring mechanism for teachers' classroom quality. Up to now, the total number of lectures in the whole year has reached 1186, with an average of four lectures for each teacher. In the whole year, $100 \%$ full coverage of teachers' lectures has been achieved, which has standardized teaching behavior and improved teaching management level. The teaching ability of young teachers has been significantly enhanced, the classroom effect of teachers has been significantly improved, and the teaching quality has been greatly improved.

\section{E. Students: Leading by the Golden Key Project, Three Promoting Projects, and Improving the Ability of Students' Literacy}

1) Leading the golden key project to improve students' humanistic quality: The school implemented the "golden key" project for the growth of college students and formed a campus culture with the main characteristics of community culture. The school has 66 associations of all kinds, and extensively carries out activities of science and technology, art, literature and art, sports, public welfare and other categories, with the participation rate of students reaching $100 \%$, the effect of using culture to educate people is remarkable. The members of the association won more than 50 awards in the provincial humanistic quality competition, one student won the South sword championship of the Chinese college martial arts championship, and the logistics sandbox Enthusiast Association won the first prize of the national level in the 10th "Changxiang Cup" national vocational college innovation and entrepreneurship competition "enterprise management sandbox Simulation Competition". Liu Duyuan was awarded the title of "top 100 college student Party member of Hunan Province" and 8 associations were awarded the titles of "top 10 associations" and "top 100 associations" in the 2018 Hunan College Student Association employment and entrepreneurship ability challenge competition, which greatly improved the students' humanistic and professional quality.

2) Promoting the students' professional ability by promoting the three projects: The college will continue to carry out the three promotion projects of promoting teaching by competition, scientific research by competition and learning by competition. The participation rate of teachers and students in various skill competitions at school level, provincial level and national level reaches $83 \%$. In 2018, the province's professional skill spot check and graduation design spot check are all $100 \%$. New breakthroughs have been made in the national skill competition, with a total of 21 awards, among them 5 first prizes, especially the internet of things application technology won the first prize in the national vocational skills competition, and the spirit of students' craftsmanship has been constantly highlighted, and their professional ability has been significantly enhanced.

\section{CONCLUSION}

In a word, the diagnosis and improvement of teaching work is a working process in which the school finds its own shortcomings, perfects and improves according to its own reality. It is a process of normalization, periodicity, continuous discovery of problems and rectification and improvement. Hunan modern logistics college promotes the development of schools by carrying out a series of projects such as "three projects", "three promotion projects" and "golden key projects" to enrich and refine school management and construction, effectively stimulate the vitality of school management, and effectively enhance the quality of school education and teaching and the ability of social service through strengthening system implementation and performance evaluation. The completion rate of the annual work tasks of the school party committee and the headmaster' $s$ work report is more than 95\%, and an effective operation mechanism of the school quality assurance system has been established. The school's various undertakings present a scene of thought contention of hundreds of factions and all flowers are blossoming together, continuously promote the construction of the school's connotation, and the quality and level of personnel training are improved year by year. 


\section{REFERENCES}

[1] Chen Shougen; Wan Liya. Connotation, Construction Principle and Practice Mode of Internal Quality Assurance System in Higher Vocational Colleges $[\mathrm{J}]$. Vocational and Technical Education. January 1, 2017. (in Chinese)

[2] Ye Zhu. Connotative Development: Understanding and Practice of Open Education Quality Assurance System Construction [J]. Lifelong Education Research. March 21, 2019. (in Chinese)

[3] Chen Shougen. Connotation, Framework and Construction of Professional Quality Assurance System in Higher Vocational Colleges [J]. Vocational and Technical Education. September 1, 2014. (in Chinese)

[4] Chi Yunxia; Wang Zhenjie; Zhang Shuyan. Study on the Construction of Internal Quality Assurance System in Higher Vocational Colleges From the Perspective of Diagnosis and Improvement [J]. Vocational and Technical Education. June 11, 2019. (in Chinese)

[5] Yi Miao. Thoughts on Realizing the Early Warning Function of Internal Quality Assurance System [J]. Vocational Education Research. 2017-01-01. (in Chinese)

[6] Chen Shougen; Wan Liya. Connotation, Construction Principle and Practice Mode of Internal Quality Assurance System in Higher Vocational Colleges [J]. Vocational and Technical Education. February 8, 2019. (in Chinese)

[7] Xia Lu. Research on Data Collection and Management of Talent Training Status in Higher Vocational Colleges [J]. Higher Education Forum. January 20, 2019. (in Chinese)

[8] Li Haiping. Connotation, Construction Principle and Cultivation Path of Quality Culture in Higher Vocational Colleges [J]. Journal of Baotou Vocational and Technical College. March 15, 2019. (in Chinese)

[9] Ma Guoqin; Liu Danqing. OBE Oriented Higher Vocational Education Diagnosis and Improvement Mechanism Research [J]. Vocational Education Forum. June 15, 2019. (in Chinese)

[10] Zhou Yan. Research on the Development of Vocational Skills Appraisal Training System Based on "Diagnosis \& Improvement" [J]. Modern Vocational Education. January 28, 2019. (in Chinese)

[11] Tan Jieqi. A Probe into the Construction of long-Term Mechanism for the Cultivation of Teaching self-Diagnostic Ability of Full-time Teachers in Higher Vocational Colleges [J]. Research on Vocational Education in Xinjiang. 2019 -03-15. (in Chinese)

[12] Yang Bo. Thoughts on the Diagnosis and Improvement of Teaching Work in Higher Vocational Colleges - Taking the First Batch of Pilot Colleges of Higher Vocational Diagnosis and Reform in Hubei Province as an Example [J]. The Science of Leadership Forum. September 16, 2019 1. (in Chinese)

[13] Zhou Baochun. Investigation and Enlightenment of Teaching Diagnosis and Reform of Middle Vocational Schools in Guangdong Province - Based on an Investigation of Middle Vocational Schools in Foshan and Guangzhou, Guangdong Province [J]. Guangxi Education. 2019-05-10. (in Chinese)

[14] Du Qian.A Preliminary Exploration of the Internal Quality Assurance System in Higher Vocational Colleges [J]. Journal of Liaoning Agricultural College. November 8, 2018. (in Chinese)

[15] Zou Jiyan. Discussion on the Practice Path of Diagnosis and Improvement in Higher Vocational Colleges [J]. Mechanical Vocational Education. September 15, 2018. (in Chinese) 